\title{
The turn to overall sustainable social transformation: does it real?
}

\section{Arkady Martynov}

Abstract. The paper is devoted to fundamental issues concerning to the ideology of the future sustainable development. Its implementation has available in the first place basing on the recognized framework concept of sustainable development (SD). At the same time, this concept requires serious improvement. As follows from the argumentation, a realistic design of institutional changes in connection with resource and organizational/behavioral changes needed for SD is called for to realize in the line of overall social system transformation. Its adequate understanding presupposes an exhaustive study of interconnected transformations in the main social fields as system processes taking into account the influence of relatively exogenous factors (technological, demographic and climate changes).

According to the author, the transition to global sustainable social transformation is achievable. Main attention focuses on a number of possible fundamental shifts, the synergetic implementation of which will make such a transition possible.

Proceeding from the arguments, the sustainable reproduction of the economy of a mature post-industrial type, including the green sectors, implies its stable and quiet growth, although the rapid growth of individual markets, especially innovative ones, may take place. The main findings also include the substantiation in favor of the choice of the national middle way model as the most appropriate for the corresponding sustainable system transformation of society.

Key words: social system, sustainable transformation, institutions, technologies, demographic and climate changes.

Doctor of science (Ph. Degree)

Institute for social development, Institute of economics (Russian academy of sciences)

Malya Lubanka Str., 16/4, 101000, Moscow, Russia

Voice: +74956288319, Fax: +74956245098

E-mail: socpolamv@mail.ru

Personal page: http://viperson.ru $>$ wind.php?ID=625498 


\section{Introduction}

Until recently, world development in the present post crisis decade has characterized by a lack of significant technological and institutional progress. In the current period, the growth of capital in conventional markets is the most significant factor of economic development in almost all developed countries. Macro effect of growth of existing high-tech and knowledge-intensive capital and, in particular, investments in information technology of today's generation actually reached saturation for a long time ago. In general, an almost gloomy picture of the stagnation of technological and institutional progress has taken place, judging, at least, from the dynamics of indicators recognized at the international level - total or multi-factor productivity. In fact, the inertial trend of economic development unambiguously prevails.

The phenomenon of the world migration tide, which exceeded $3 \%$ of the total population of the planet, is still stunning. Fundamentally it is due to the gap between consumer and cultural demands and the opportunities for their satisfaction of citizens of poor and, especially, of crisis countries. Visiting many countries one can see an excessive influx of migrants in relation to the needs of the national economy, given the downswing in economic globalization. The disproportion between the ever-expanding wave of world migration, on the one hand, and the slow growth of global and multi-regional markets, along with stagnation and even a decline in the scope of foreign direct investment, on the other, is becoming ever more threatening.

Under such circumstances, the second advent of neoconservative capitalism, oriented to the maximum turnover and profitability of national private capital in traditional, non-high-technology and non-science-intensive sectors, seems quite understandable. In turn, the implementation of these goals well combines with economic nationalism creating the conditions for the maximum competitiveness of producers in respective countries.

Certainly, the current aggressive neo-conservative course, conducted by the US administration, brought only temporary successes. It is widely believed that in the long term the outcome of this course will be negative. By the end of next year, the incentive effect of lowering taxes on business will probably exhaust, and, conversely, the effect of a response increase in foreign tariffs will increase. As a result, government spending will need to reduce accompanied by the inevitable increase in FRS interest rates. Therefore, there will come a phase of a prolonged recession taking into view the influence of cyclical factors.

In the geopolitical space the factor of force, which determines the disgust anomalies at the interstate level, is definitely prevailing. Consequently, the pessimistic expectations of the unconditional transformation of the factor of power into the dominant in 
international relations and the complete restoration of the hegemonic duopoly including the United States and its closest allies, on the one hand, and China-Russia, on the other, are understandable. Then there will be a split of the world, in the institutional sense more profound in comparison with the era of confrontation between the Western and Socialist blocs in 1960-1980.

Without exaggeration, the world community and the majority of its members sovereign countries - face a choice of urgent and fully realistic long-term solutions that allow them to concentrate their efforts on overcoming the arisen barriers to progress. To justify these decisions, it is necessary to take into account a whole series of processes of economic and other social changes associated with fundamental, not short-term structural shifts - institutional, technological and others.

The great desire, as if to counterbalance the unfavorable conjuncture of this day's development, concludes to outline a possible transition to a positive global future, albeit achievable through overcoming difficult obstacles. Let us try at least partially to expose this plan.

The indicated task predetermined the logic of the structuration of the paper. In its initial part, the conceptual vision of social progress is justified from the standpoint of the theory of social transformation. Further in the article the key question is considered about the possibility of overcoming the existing global regress for the transition to a sustainable overall social transformation. The following parts of the article are devoted to the sketch presentation of a sustainable social system transformation along its main lines. In addition to this, the issue of choosing the national institutional model that is most suitable for sustainable general social transformation specially considers in part 5 . Concluding remarks present in the final part.

\section{A conceptual vision of overall social progress}

It seems reasonable to refer to the theory of social system transformation, relying on recognized outstanding contributions [Polanyi 1944, Parsons 1951, Giddens 1984, Luhmann 1995]. In accordance with this theory the research paradigm, concluding in the treatment of the development of the social system as a transformation of its multidimensional structure, is legitimate. This approach assumes an integrative representation of the significant components of the development vector of a particular society as a social system in a real time-space dimension.

Transformation of the social system in its traditional (narrow) understanding encompasses the main fields of social action, economic, political and societal (status), characterized by the existence of a defined institutional design and resource provision. At the same time, it is necessary to take into account that social changes in institutionally 
structured fields have inevitably accompanied in large degree by non-institutionalized processes of technological, demographic and climate changes.

Thus, social system transformation occurs in a result of the interaction of endogenous institutional/resource shifts, as well as a variety of exogenous processes. Such as the invention of fundamentally new technologies, the change of cycles of solar activity, etc.

The initial premise of the system transformation concept of progress development lies in the permanent change of production, personal and social needs, based on achievable new resource, institutional and technological capabilities, expected demographic and climate changes [Martynov 2016]. These requirements, in turn, predetermine the multi sector vector of potential economic output and the vectors of long-term shifts needed in other fields of social action. They are the objective guidelines for the fundamental development of the social macros as an integral system, in the direction of which, under the necessary conditions, the desired transformations can occur in accordance with the criterions of progress. At first place the criteria for improving well-being in its broadest sense, taking into account the state of the human environment. Following the internationally recognized position, the integrative welfare of the society has reflected in the indices of the quality of life and human development as so as in the happiness (subjective well-being) index.

Without resorting to obvious mathematical proofs, one can assert. Grounded on the well-known criteria of optimal inter-temporal ratio of costs and outputs, the transformation of social macros as a system on a stable and plausible long-term trajectory is preferable. Its immanent feature is not a spasmodic, but a steadily consistent movement to the achievable transformation boundaries, based on the identified opportunities.

Thus, in order to justify the concept of future social progress, it is logical to expose a universal idea of integrative sustainable development, moreover, as applied to the system (precisely system!) transformation of the whole society. Following this approach, an inalienable feature of the desired development of society as an all-encompassing social system refers to a sustainable transformation. It expresses in the reproduction of the promising development vectors of the overall social system, which, according to the recognized criterions, believed to be sustainably acceptable.

Judging by the harsh contemporary realities, with respect to the national interests of individual countries the imperative of sustainability has most clearly manifested in the guarantee of maintaining an acceptable quality of life and well-being levels. This is attainable through the interaction of all public forces, including corporate and other businesses. Nevertheless, the main responsibility in the constant ensuring the sustainability of the national development results put unequivocally on the state. 
This role of the state as a guarantor of sustainable development is definitely incompatible with neo-liberalism, as well as with the neo-conservative capitalist doctrine. The same concerns the ideology of modern corporatism. The effect of charitable activities, called socially responsible, of large corporations is inevitably limited.

It makes sense to clarify. The desired transformation of society is not fully exhausted by the processes of sustainable change. It can include processes of more progressive changes that act as the results of initiative decisions of purely market agents and social entrepreneurs under the condition that sustainable development trajectories prevail in the main fields of social action.

Undoubtedly, the indicated initial approach to the design of future social progress should be based on the framework concept of sustainable development (SD), long ago recognized by the international community [Enders and Remig 2015]. Its latest version has presented in the official memorandum "Transformation of our world: An Agenda for Sustainable Development for 2030" or simply an Agenda adopted at a special UN summit in September 2015.

As is known, the UN framework concept of SD is integrative. Achieving the set goals in principle supposes to be equally priority and interdependent within the 15-year perspective (2016-2030).

The fundamental innovation concludes in the statement of the imperative to create effective institutions at all levels, recorded in Agenda Goal 16. Almost decisively successful integrative SD, according to the adepts of the renewed concept, acquires the phenomenon of the spread of inclusive institutions [Global Sustainable 2016]. These institutions, mostly based on the principles of universality and non-discrimination, provide equal rights and opportunities for producers and consumers, as well as access to all resources and services. They are confronted by exclusive institutions that ensure the withdrawal of resources in favor of groups that have economic and political power at the expense of the rest of society [Acemoglu at al. 2015].

As stressed in the Memorandum of the G-20 Summit in China [G-20 Action Plan 2016], the necessary step concludes in approving a suitable institutional environment for inclusive non-dependent business including social entrepreneurship. Exactly the inclusive business is called upon to play a key role in implementing the imperatives of future sustainable development.

At the same time, by opinion of many researchers (the author among them), the current concept of SD is selectively segmental and in fact far from the system one. It mainly focuses on environmental and humanitarian issues, the conservation of natural resources and the use of reproducible resources, overcoming the consequences of climate degradation, improving the efficiency of individual institutions. Opposite to it, the problems of fundamental institutional reforms and adaptation to fundamental 
technological changes have only fixed using previous traditional formulations. Namely from the resolution of these problems, the possibility of achieving sustainable acceptable production, consumption and employment trajectories depends to the greatest extent, as well as achieving purely ecological, climate and humanitarian targets.

In our opinion, the treatment of inclusive institutions, represented by the adherents of the framework concept, also needs a serious adjustment. It should be borne in mind that not all effective institutions needed for sustainable development are inclusive; moreover, not all can be incorporated into the framework of contractual relations. That has been said above primarily concerns the institutions of public regulation. Many of them, in principle, are not inclusive, such as progressive taxation rules. Also, key institutions that function in corporate and other limited competition markets, a number of informal political institutions and, to a large extent, informal social norms conditioned by the specifics of national development are certainly not inclusive.

Even more significantly, the describing concept in question is not essentially a transformational in the institutional projection. The desired patterns of inclusive institutions as if have a priori fixed, although their development supposes largely due to a purposeful public policy at different fields of social action.

The realistic design of institutional changes in connection with resource and organizational-behavioral changes needed for sustainable development is called for to base on an exhaustive view of transformations in the main social areas. In line with the overall social system transformation, the time-space positioning of institutional and resource changes taking into account the influence of institutional/resource changes on the "adjacent" fields of social actions and relatively exogenous factors (technological, demographic and climate changes). As a result, an adequate reflection of the integrative transformation of the entire vector of parameters of the social system becomes possible, proceeding from the imperatives of sustainable development. Besides, we should especially note, the attainment of ecological improvements and relative climate stabilization depends on an assumed integrative consequence of all transformational shifts.

\section{Transition to global sustainable social transformation: possible fundamental shifts}

The position in favor of achieving a steady progressive development of the world community within the framework of the main social fields as an integral condition of such a transition looks unquestionably constructive. It is appropriate to focus attention on a number of possible fundamental shifts, the synergetic implementation of which will result in the overhaul of the regressive trajectory of global development. 
The first shift. Exclusive importance for improving the state of the world economy and geopolitical situation will have a successful embodiment of the idea of the implementation of the ripe "new deal", which has now become a popular expression, in the EU countries, to which Japan deserves attention. The great economic, innovative and human potential of the countries-conductors of European integration in its new capacity allows us to hope for success, despite significant centrifugal processes.

The crucial point is the implementation of a new European defense program initiated by France and Germany. The EU needs to be armaments capable of curbing the potential aggressor by an adequate preventive / retaliatory strike. Large-scale developments in this direction can bring, judging by the example of China and Russia, to a practical positive result in the short term.

The second shift. The grandiose economic expansion of the Celestial in a nonWestern world will be even stronger on all grounds. It is manifested in the increase of economic growth and consumer welfare in many countries. As known, Chinese leaders are in favor of an early reform of the world monetary and financial system. It may become an important step towards the establishment in the future of a fair economic order at the global level.

The third shift. India, Brazil, Indonesia and a number of other post developing countries with their combined enormous potential are definitely capable of achieving significant economic and humanitarian progress in the short run perspective. At the global level, it will visibly be reflected in the long-awaited reduction in poverty and the income gap.

Also in the short term, it is possible to predict the political progress in many countries of Latin America. Favorable economic, and with them, political shifts will probably occur on the African continent.

The fourth shift. The problem of adaptation of scientific and technological achievements in various economic and social sectors can be successfully resolved through a large-scale and simultaneously selective innovation policy, especially in the leading European countries, China and Japan. Then it will be difficult to reevaluate the global effect in the coming period of the diffusion of new digital and other technologies called the fourth industrial revolution, which will manifest itself in the global innovation/technological progress affecting most of the countries. The prevailing trend of inertial development of the world economy will be overstrained.

The fifth shift. Based on a broad international consensus, an adequate response to the global migration challenge can be given. A firm, justified migration policy, while taking into account humanitarian values, is asserting itself. The achieved agreement on the positions of the EU countries on migration policy issues is a convincing confirmation of this. 
At the same time, intensive financial assistance to developing countries and the most active participation in the reform of their economies and social sectors by the EU, Japan, China and other industrialized countries remain extremely necessary. As a result, the number of weak, politically dependent states will drastically decrease, which will entail a radical weakening of migration anomaly.

The final shift. The joint efforts of the progressive governments of developed and other countries to stabilize the climate, predetermined by the Paris Agreement in 2016, and the improvement of the environment will be crowned with considerable success. Then probably there will be real world recognition of environmental and other imperatives of sustainable development, ultimately affecting the United States and Russia, as well as the entire post-developing world.

Ultimately, in the event of these transformational changes, on a global scale the factors of progress will obviously prevail over the inertial factors in the economic space and the increase in social welfare in its broad sense for the citizens of most countries will become a constant trend.

It is equally important to achieve an unsurmountable political progress. Thus, in the consequence of the creation of a powerful defensive shield of continental Europe the factor of military potential will cease to play a dominant role in the world balance of power. This balance will form depending on other significant factors of economic and political weight of different countries and their alliances. The notorious duopoly of power over the world will not take place despite the possible preservation of confrontation between the US / NATO and the military alliance Russia-China.

\section{Towards a sustainable social system transformation in the twenties}

The system presentation of a sustainable transformation of society implies the coverage of all significant areas of social development in their integral unity at the national, regional and global levels. Apparently, two main criteria signs of this process can formulate in the following way. First, the formation of stable long-term trajectories of the main resource, as well as fundamental institutional and organizational shifts in the direction of the required structural target points for the future, reflecting the entire set of environmental, special humanitarian and other parameters of sustainable development. Second, reliable adaptation to the expected technological, demographic and climate changes insofar as they act as exogenous factors with respect to the transformation of the entire social system and its main components.

At the same time, one cannot fail to take into account the existence of a huge number of processes of non-stable changes, bearing in mind at least cyclical fluctuations of the market situation, the impact of technological shocks, sporadic political 
perturbations and social conflicts. They can be count-progressive and have a very significant impact on economic, political and societal fundamental changes, leading to a violation of the conditions for a stable systemic transformation. Therefore, apparently, the problem of neutralizing such influence in the future will be central to the design of directly long-term strategic solutions and mechanisms for overcoming emerging risks [Transformation towards 2018].

Let us try to imagine lapidary at least a sketch vision of the future sustainable social system transformation along its three main directions - economic, political and societal.

Sustainable economic system transformation. The expected future changes in the twenties will lead to a rethinking of the understanding of sustainable economic development as an uninterrupted time-space transformational process. The most significant contribution to the economic output is called upon to make technological and institutional progress. He acts as the main means of ensuring the long-term competitiveness of national economies, but not the aggressive protectionist policy following the current American model.

The unfolding of new industrialization opens the way for the maximum reduction in the consumption of hydrocarbons and other renewable resources and their replacement by reproducible green technologies in the grandiose dissemination and the implementation of efficient infrastructure projects, specifically on environmental criteria. Consequently, the desired significant effect of decoupling will achieve, when economic results grow much faster than consumption of resources and the scale of their impact on the environment.

Apparently, on a global scale, there will be a long-awaited structural shift towards the prevalence of innovative and high-tech economic sectors, where reproducible resources and energy efficient, waste-free and low-waste, technologies will use. In addition, we can expect the establishment of a green economy in most of the world that meets the imperatives of environmental sustainability and climate improvement. Already there are a significant number of economically and environmentally effective green technologies ready for widespread use. This gives grounds to hope for a gradual (exactly gradual) elimination of the existing brown economy. A long-awaited consequence of a drastic reduction in the consumption of non-renewable resources will be the conservation of biodiversity and the enhancement of natural capital based on the restoration of ecosystems and spread of new one.

At the same time, it is definitely unacceptable to simplify the problem of market adaptation to new technologies in the incoming future [Körner at al. 2018]. As evidenced by numerous facts, the applying of a number of new technologies, including digital technologies, in principle does not meet the criterion of economic stability. Quite 
likely the shock effect of the development of individual markets, where these technologies implement, will take place. According to a number of researchers, the consequences of the use of robotics and technologies based on artificial intelligence will have a painful impact on labor markets.

In the long term, there will be a long-term need for the creation of special regulatory mechanisms. At first place, it implies the dissemination directly in the market environment of new adaption technologies, which are beginning to be developed.

The inalienable imperative of a sustainable system transformation is the maintenance of employment in the market and social sectors in full accordance with the Agenda. The burning problem of reducing the relative proportion of able-bodied contingent in the population of developed countries due to its aging is likely to be resolved to a significant extent due to the regulated influx of foreign labor on a strictly legal basis.

The future SD is also supposed a fair pay of labor including gender wage equality. If this condition is fulfilled a desired reduction in the differentiation of income and personal/family wealth will be achieved, as it follows from regional studies.

In the observed perspective the increase in the capital and incomes of innovators and producers in high-tech sectors can happen to the greatest extent. Conversely, a relative reduction in the capital of financial entities and rental incomes is desirable, accompanied by the elimination of hypertrophied high-yielding components and broad niches for financial speculation. At the same time, an essential condition concludes in maintaining financial balance with reference to individual national economies. Especially in the implementation of future long-term structural reforms [G-20 Enhanced 2016].

In addition, proceeding from a number of forecasts, the current regime of a tight monetary stabilization policy will probably preserve. It should complement by neutralization of illegal / criminal economic activity and anti-corruption course on a recognized legal basis.

At the global, multi-regional and national levels, the assertion as dominant precisely the sustainable economic order is called for. It assumes an unhindered stable trade regime, as well as stable regimes of the international movement of capital in its various forms and labor and, besides, most importantly, acting on the base of coordinated application of global, regional and national legislation. Certainly, they are not compatible with the former liberal (of course, only in words!) international economic order of the era of American hegemony, the return of which is still pinned on by certain backstage circles.

It can be assumed that on the world stage, at least three competing groups of countries will be comparable in market potential: 1) the United States and other countries with the prevailing capitalistic institutional order; 2) China, India, Russia and a number of other non-Western countries; 3) the countries of continental Europe, 
apparently, in alliance with Japan and Canada. At the same time, the role of regional economic unions, which includes other countries, will remain highly significant. In conditions of such multilateral international competition, there are grounds to assume that most countries will act as equal rights members of the world economic community. In turn, the establishment of such an equal right order will serve as a prerequisite for further movement towards full-scale economic globalization.

Of course, we should not question the need to maintain a positive world economic dynamics for the sake of the well-being of the entire human society, as recorded in the G-20 memorandums in recent years. At the same time, it makes sense to pay special attention to the weighty arguments in favor of maintaining a relatively moderate rate of economic growth in the period of the twenties.

The first argument is quite understandable: the priorities of sustainable development dictate the feasibility of qualitative improvement of most of the existing markets with their limited resource growth. It becomes achievable because of a mutually complementary combination of two processes: the introduction of new technologies that minimize the cost of resources and the widespread use of reproducible resources and the spreading of non-waste production in technologically "old" sectors.

The second argument: for the reproduction of the potential of the mature postindustrial economy, the maximum quantitative growth of new technologies and new machinery is not required. For example, the demand for new information digital technologies and computers will be limited, at least in terms of the number of their customers. In addition to this, one should take into account that, according to all forecasts, in the twenties the tendency of relative cheapening of technology will increase (in terms of the ratio of selling prices and useful effect). Also in this perspective, probably, there will not be a need for a very rapid growth in the physical volumes of buildings, structures and other objects of the infrastructure of the post-industrial economy. The compactness and ergonomics of most of the high-tech enterprises with the continuation of the trend of miniaturization of technological progress is a very weighty argument in favor of this assumption.

As for personal and family welfare, the direction of the transformation of its structure in the long term will most likely predetermine changes in rational consumer preferences. The value of the quality of life in the environment conditions of the 21 st century comes to the forefront. It involves a rational personal consumption of resources that does not harm the environment. Comprehension of the meaningless to use for the sake of prestigious reasons a lot of cars, suburban buildings for the construction of which a huge mass of "brown" building materials is used, and other attributes of luxury life that are harmful to the environment, will become, perhaps, a fundamental feature of the future consumer ideology. 
Finally, another weighty argument against the maximization of economic growth is due to the expectation of further institutional improvement in the main domestic markets in non-Western countries. According to all projections, in the considered perspective the rate of profit in real sectors of their economies will decrease and will approach the existing level in Western countries. It will first happen in China, then in other Asian giants and, ultimately, in most of the rest post developing countries. The rapid growth of most commodity markets caused by opportunistic and, especially, speculative financial factors will not be observed and, accordingly, market participants will not have an interest in maximizing the accumulation of capital.

And, probably, it is necessary to put a dot over and. Sustainable reproduction of the future world economy of the post-industrial type in the twenties suggests its stable and calm, absolutely non-explosive growth. At the same time, the rapid growth of individual markets, especially innovative ones, will be quite real.

However, as if in the end of the economic theme it is appropriate to make an important observation. Sustained favorable economic changes, objectively achievable in large part due to a purposeful national or supranational economic policy, should not be interpreted as ideal or perfectionist processes. They serve as necessary conditions for the implementation in principle of the most effective resource and institutional shifts initiated by the optimal initiatives of the market agents themselves in terms of technological innovations and a wide variety of investments, the use of productive capacity and qualified personnel.

Sustainable system transformation on the political field. Let us now dwell at least briefly on the very fragmentally studied topic of sustainable transformation in the political field. It involves not only internal political stability, which is usually considered as a condition for maintaining the favorable economic development of certain countries.

Undoubtedly, the position in favor of the formation at the global level of a multipolar political order is incompatible with the hegemony of one country or group of countries, as well as with a superpower duopoly (the United States and its closest allies, on the one hand, and China and Russia, on the other). Such an anti-hegemonic order can become the basis for satisfying the national interests of small countries.

It will be necessary to create flexible, time-mobile institutional mechanisms, including organizational structures, ensuring international security. Besides an obligatory condition for global political stability is the approval of the international legal regime.

Institutions providing stable internal political transformation of individual countries on the principles of democratization and competition are well known [Mazarr 2018]. According to national studies, the effectiveness within the political institutions directly depends on the quality, that is, the results and costs of administrative management at all its levels. 
The positive impact of the formation of a stable economic order on transformation in the political space will first manifest itself in the long-predicted shift. The political elite will be largely replenished by higher management in the innovative and high-tech corporate sectors, as well as in the sectors of the new economy of reproducible resources, while reducing the presence of leaders of financial and trade capital.

At the same time, it worth noting that the achievement of a stable trajectory of political transformation would not mean a general transition to a perfect regime of democratic governance in civil society in accordance with traditional ideas. Especially in relation to countries that are not democratic in reality. Nevertheless, there will be grounds for hoping for an irreversible endorsement of parliamentary democracy in place of a populist, permanently primeval form of presidential rule in this large group of countries.

Sustainable societal system transformation. Now let us turn to the extremely multifaceted problem of sustainable transformation on the societal field. Its integrative criteria condition, following the recognized notions, considers the fair distribution of wealth in its broad sense (including consumption of natural and cultural goods, education) among all generations of citizens accompanied by a constant improvement of quality of life with reliable social balance.

This kind of transformation should be associated with gradual positive improvements in the status pyramid especially non-deviating strengthening of the middle class positions. Then, in the case of the parallel formation of a sustainable economic order, the composition of higher status groups (including the so-called transnational corporate class) will constantly update.

However, it is worth acknowledging that realistic design of improvements to the status pyramid of society represents a very complex problem. To solve it, it would be necessary to assess the impact on the status pyramid transformation of economic and political institutional progress, as well as the impact of technological and other exogenous off-system changes. In particular, economic progress should be associated with a reduction in income inequality. Under this outcome, as recent studies confirm, for example [Arita 2017], there will be an improvement in the stratification structure in terms of the criterion of social well-being.

Crucial value, as the practical experience suggests, will be the realization of the synergetic effect of mutually complementary decisions in different areas of social policy with the inherent participation of business and public independent organizations. Surely, the expected progress in the field of combating poverty and in the educational sphere is called for to materialize in a significant improvement of the natural environment. In turn, it is extremely important to achieve the opposite effect of these improvements on the state of the entire national society. The favorable ecological conditions of life 
manifest as the weighty factors of the life stability in local communities and, consequently, of social stability in certain national borders, when the principle "to live at home, rather than to seek abroad" triumphs.

Judging by today's experience, the stimulation of various forms of voluntary participation of citizens in public activity becomes critical. It prevents social exclusion of certain groups of the population, in particular, the spread of youth drug addiction. Mass participation of migrants in the activities of public organizations is also of great importance, for which special educational and cultural programs are extremely necessary.

Ultimately, the satisfaction of the growing intellectual, moral and spiritual demands of citizens of modern countries presupposes a favorable cultural transformation while maintaining the divergence of national (subnational) cultures. Social policy along the lines of a sustainable system transformation should promote the orderly strengthening of the solidarity in society. Then, despite possible problem demographic and migration trends, the much-desired tightening of the integration of various national communities will be achievable.

It is also reasonable to count on the widest distribution of post-materialistic consciousness among representatives of educated and ensured stratums of society. Their preferences will predetermine by values expressed in freedom of expression and quality of life. Post materialists put personal entrepreneurial success and the accumulation of individual wealth along with professional achievements and long-term well-being within the human and natural environment. Besides, entrepreneurs who share this ideology will guide by the social recognition of their sustainably effective business.

However, it would be a mistake to succumb in short mind manner to the illusion of a quite favorable social arrangement for the future. In the twenties, despite the likely spread of the post-materialist worldview, there is every reason to expect an expansion of routine, completely non-creative economic and other social activities in the conditions of using unoccupied digital-led technologies and robot technologies. A huge number, and possibly most of the employed, will be concentrated in low-tech and mediumtech activities in the service sector. The threat of preserving the non-creative needs in the life of these employers will become very significant.

Apparently, the way out to the decisive extent connects with the possibility of a radical increase in employment, including the various intellectual activities, in the social environmental sector. It will present a wide area for the use of new technological innovations as public goods. This process is designed to become comprehensive, covering the growing megacities and ordinary cities, as well as the climatically challenging regions of the planet. 


\section{Choice of national institutional model}

The central question concerns the establishment of the root institutional envelope of the desired transformation of the social system, which primarily meets the conditions of sustainability. Achieving the desired benchmarks for a sustainable transformation of innovation and high-tech sectors, as well as sectors of the green economy, requires the effective complementarity of traditional market and other institutions: first of all, institutions of state and state-private, corporate and private unincorporated entrepreneurship.

Therefore, we can assume. The national model of the middle development path or middle way, the initial idea of which had expressed by Henry George [George 1879] even in the period of the formation of classical capitalism, corresponds to the condition of effective institutional complementarity in the future. This model characterizes precisely by the balancing of state, corporate and independent entrepreneurial orders with the paramount importance of the principles of socially effective activity and socially equitable distribution. In practical terms, sustainable transformation of these orders would mean a long-term stability of the economic and political course without tremendous turns to the right or left and, of course, without a radical change in the state system, as in the present period of tenth.

The following point is crucial. The approval of strong institutional mechanisms that ensure private, corporate, state and social entrepreneurial initiative fully corresponds to the character of the coming period of the expected grandiose technological changes in the twenties. Proceeding from the experience of Sweden, Norway and Singapore, the favorable adaptation to the markets of Progress technologies, including green technologies, had taken place due to the median institutional arrangement of the economic system and the overall social system.

As we know, the institutional model of the middle path of development has been successfully adapted in the Scandinavian countries and East Asian countries - Malaysia, Taiwan and Singapore. Therefore, one can believe that a gradual transition to this model in many developed countries will become possible especially in case of successful reform course in France and Germany.

The likely transformation of the current model of the symbiosis of state capitalism and market socialism in China into a certain model of the convergence of "socialism and capitalism" [Schumpeter 1942, Galbraith 1966], which is in fact a variation of the middle way model, will also have great significance. The weightiest argument in favor of this assumption is quite understandable. With regard to the medium-term prospects for the development of the Chinese economy, the key shift required is to free the corporate sector from state dictates and reduce the public sector itself, with a radical expansion of the space for independent entrepreneurship, including innovation business, in 
accordance with the requirement of world market competitiveness. This need extremely enhances due to the decrease in the export advantages of the Chinese large corporate sector based on cheap labor and economies of scale, with a possible reduction in foreign investment, as well as the severity of regional problems, mainly in the west of the country with its poor peasant population. As a result, transformational shifts may occur that are sufficient to form a balanced institutional structure after socialist economy in accordance with the model of convergence. State capitalism as an institutional order apparently will remain, but it will not play a hypertrophic high role and undermine other institutional orders.

In this context, it makes sense to stay, at least briefly, on an important collision. Institutional arrangements characterized by the prevalence of capitalist institutions, especially corporate capitalist ones, are likely to continue in a number of countries. However, these countries will not receive the same advantages in the economic arena in terms of capital growth, income, consumption and employment. On the contrary, they can be a loser in the conditions of asserting a sustainable global economic and social transformation. At least, for two fundamental reasons: first, the reduction in the relative contribution of physical capital and labor, especially in the corporate sector, to economic output, as opposed to a relative increase in the contribution of technological and institutional-managerial progress, largely socialized; second, the expected slowdown in many branches of the brown economy - the main foothold of past century capitalism with its well-known institutional framework.

That said does not call into question the possible growth in the future of local real estate markets, individual luxury goods, specialty medicines and medical services (such as stem cell transplantation operations). At the same time, the role of these highly profitable markets will be limited at the world and regional levels.

If the national model of the middle path of development will prevail on a global scale, there will obviously be a fundamental weakening of the factor of institutional divergence. Thus, the main obstacle to the movement towards full-scale economic globalization will eliminate.

\section{Concluding remarks}

Sustainable overall social transformation in its main interconnected fields performs as an indispensable attribute of future human progress. Despite the likely weightiest costs and significant counter actions, the need for transition to this type of social development looks unambiguous.

A purposefully maintained movement along the trajectories of a sustainable social system transformation is by no means a path into a "bright future" in the spirit of 
communist ideology. New burning problems will arise before the planetary community. Definitely implementation of strategic plans of progressive development, at first place sustainable development, in the period of the twenties will come across serious various obstacles - sources of risks. Suffice it to say about the threats of tech-gen disasters (the uprising of robots with artificial intelligence is no longer exclusively a topic of fantasy literature), unexplored before epidemics and ethno-national conflicts. However, these obstacles, if the ideology and practice of sustainable development has established, will be overcome in an acceptable way without long crises and immense social damage, on the base of global, regional and national consensus.

In regards to individual countries, the substantiation of realistic feasible support for the main areas of the sustainable social system transformation will be an important initial step towards the development of a national development strategy. Judging by international experience, it is definitely expedient to fix the benchmarks of sustainable transformation and other transformations within the framework of the system development strategy embracing the whole society. It calls for the identification of ways to achieve the future, which the majority of the national society desires and deserves.

At the same time, it is worthwhile to remain realistic. Processes of deliberately unstable, accelerated transformational changes are called upon to account within the certain directions of the national development. For this purpose, special strategic approaches should approbate in practice.

Obviously, the implementation of overall social transformation national strategies can provide the positive impact on the current design practice and public monitoring of the selected SD targets [The Sustainable Development 2018, Global responsibilities 2018]. Due to the integration of these strategies, the possibilities of achieving these benchmarks in time as well as in space can assess for different countries and at the global level.

\section{REFERENCES:}

Acemoglu, D., Liabson, D. and List, J. 2015. Why Isn't the Whole World Developed? // Chapter 8, in Macroeconomics, Pearson. Available online: http://pearsonhighered.com/acemoglu-econ

Arita, S. 2017. A Comparative Analysis of Social Stratification in Japan, Korea and Taiwan. Tokyo. Institute of Social Science. University of Tokyo. Available online: http://iss.u-tokyo.ac.jp/publishments/dpf/pdf 
Enders, J. and Remig, M. (Eds.). 2015. Theories of Sustainable Development // Abingdon: Routledge.

G-20 Action Plan on the 2030 Agenda for Sustainable Development. 2016. Geneva. Available online: htpp://ictsd.org.

G-20 Enhanced Structural Reform Agenda. 2016. Available online: http://mofa.go.jp/files/000185875.pdf

Galbraith, J.K. 1967. The New Industrial State. Boston: Houghton Mifflin.

George, H. 1879. Progress and poverty. San Francisco: W.M. Hinton.

Giddens, A. 1984. The constitution of society. Cambridge: Polity.

Global responsibilities. SDG Index and Dashboards Report. 2018. Available online: htpp://sdgindex.org/.../2018/

Global Sustainable Development Report. 2016. United Nations, p. 61-76. Available online: http://sustainabledevelopment.un.org/globalsdreport/2016

Körner, K., Schattenberg, M. and Heymann, E. 2018. Digital economics. How AI and robotics are changing our work and our lives. Frankfurt am Main. Deutsche Bank Research. Available online: http://dbresearch.com/.../Digital_economics\%3A_How...

Luhmann, N. 1995. Social systems. The Stanford: Stanford University Press.

Martynov, A. 2016. The system transformation of economy and society: The Russian choice (in Russian). Moscow: Lenand.

Mazarr, M. 2018. Summary of the Building a Sustainable International Order Project. RAND Corporation. Available online: https://rand.org/pubs/research_reports/RR2397.html

Parsons, T. 1951. The Social System. London: Routledge.

Polanyi, K. 1944. The great transformation. New York: Rinehart.

Schumpeter, J. Capitalism, socialism and democracy 1942. New York; London: Harper \& Brothers.

The Sustainable Development Goals Report 2018. United Nations. Available online: http://unstats.un.org/sdgs/files/report/2018

Transformation towards sustainable and resilient societies in Asia and in the Pacific. 2018. United Nations, Asian Development Bank, United Nations Development Program. Available online: http://sdgasiapacific.net/download/SDG_Resilience_Report.pdf 